performed inferotemporally to minimise the effect on the superior conjunctiva. In addition to these two procedures, it has recently been suggested that combined trabeculectomy/trabeculotomy is superior to trabeculectomy, trabeculotomy, or goniotomy with a 2 year success rate of $93.5 \% .^{18} \mathrm{~A}$ disadvantage of the combined procedure is the fact that the sclerostomy has to be placed more posteriorly than with trabeculectomy alone, predisposing to iris and ciliary body incarceration.

Inevitably, the high success rates with any of these procedures, as in the current report by Fulcher et al, come from centres or individuals with experience and expertise with the infantile glaucomas and surgical procedures in these eyes. Of 335 eyes of 210 patients with primary congenital glaucoma treated with initial goniotomy at Moorfields Eye Hospital and followed, in some cases, for up to 30 years, $93 \%$ of eyes were still controlled at 5 years, ${ }^{16}$ the time period of the current study. Similar figures have been obtained by other specialist centres for both goniotomy and trabeculotomy and this is well summarised by Deluise and Anderson. ${ }^{19}$ However, when goniotomy, trabeculotomy, and trabeculectomy were performed on Palestinian Arab children by general ophthalmologists, Elder found a success rate at 5 years of approximately $20 \%, 35 \%$, and $55 \%$ respectively. ${ }^{6}$ By way of contrast, at a specialist centre in the Middle East, trabeculotomy had a success rate of $67 \%$ versus $54 \%$ for trabeculectomy, but with a follow up of approximately only 1 year. Significant complications such as vitreous loss and endophthalmitis occurred only in the trabeculectomy group. ${ }^{20}$ Unfortunately, because of the relative rarity of this group of conditions, none of the comparative studies of treatment techniques in congenital glaucoma have been prospective controlled studies.

So what is the best primary surgical treatment for the infantile glaucomas, particularly primary congenital glaucoma? The main message from the current paper and the literature is that these rare patients do best at centres that have appropriate experience and expertise. Performed at their best, all the techniques available have advantages and disadvantages and have potentially excellent success rates if carried out correctly. However, if referral to such centres is impossible, as may be the case in some areas of the world, then trabeculectomy (possibly coupled with a gentler antiscarring agent such as a single intraoperative application of 5 -fluorouracil or $\beta$ irradiation $)^{21}$ is probably the most appropriate primary surgical treatment for use by ophthalmologists who are not experienced in goniotomy or trabeculotomy.

PENG T KHAW

Glaucoma Unit and Department of Pathology,

Moorfields Eye Hospital and Institute of Ophthalmology,

London

1 Jaafar MS. Care of the infantile glaucoma patient. In: Reinecke RD, ed. Ophthalmology annual. New York: Raven Press, 1988:15-37.

2 Gilbert CE. Causes of blindness and severe visual impairment in children in Chile. Devel Med Child Neurol 1994;36:326-33.

3 Thylefors B, Negrel A. The global impact of glaucoma. Bull World Health Organ 1994;72:323-6.

4 Beauchamp GR, Parks MM. Filtering surgery in children: barriers to success. Ophthalmology 1979;86:170-80.

5 Hauviller V. Gonioscopic findings in trabeculectomies in young children. $\mathcal{F}$ Pediatr Ophthalmol Strabismus 1989;26:133-5.

6 Elder MJ. Congenital glaucoma in the West Bank and Gaza strip. $\mathrm{Br} f \mathrm{Oph}$ thalmol 1993;77:413-6.

7 Miller MH, Rice NS. Trabeculectomy combined with beta irradiation for congenital glaucoma. Brf Ophthalmol 1991;75:584-90.

8 The Fluorouracil Filtering Surgery Study Group. Fluorouracil filtering surThe Fluorouracil Filtering Surgery Study Group. Fluorouracil filtering

gery study one-year follow-up. Am f Ophthalmol 1989;108:625-35.
Shaffer RN. Prognosis in primary infantile glaucoma (trabeculodysgenesis) In: Krieglstein G, Leydhecker W, eds. Glaucoma update II. Berlin: SpringerVerlag, 1983:185-8.

10 Burke JP, Bowell R. Primary trabeculectomy in congenital glaucoma. $\mathrm{Br} \mathcal{F}$ Ophthalmol 1989;73:186-90.

11 Knapp A, Heuer DK, Stern GA, Driebe WT. Serious corneal complications of glaucoma filtering surgery with postoperative 5-fluorouracil. $\mathrm{Am} \mathrm{f} \mathrm{Oph-}$ thalmol 1987;103:183-7.

12 Khaw PT, Sherwood MB, MacKay SLD, Rossi MJ, Schultz GS. Five-minute treatments with fluorouracil, floxuridine, and mitomycin have long-term effects on human Tenon's capsule fibroblasts. Arch Ophthalmol long-term effects

13 Susann R Jr, Oltragge EW, Carani JCE, Nicolela MT. Mitomycin as adjunct chemotherapy with trabeculectomy in congenital and developmental glaucomas. F Glaucoma 1995;4:151-7.

14 Lanigan LP, Stuermer J, Baez KA, Hitchings RA, Khaw PT. Single intraoperative applications of 5-fluorouracil during filtration surgery: early results. Br f Ophthalmol 1994;78:33-7.

15 Feldman RM, Dietze PJ, Gross RL, Oram O. Intraoperative 5-fluorouracil administration in trabeculectomy. F Glaucoma 1994;3:302-7.

16 Russell-Eggitt IM, Rice NS, Jay B, Wyse RK. Relapse following goniotomy for congenital glaucoma due to trabecular dysgenesis. Eye 1992;6:197-200.

17 Senft SH, Tomey KF, Traverso CE. Neodymium-YAG laser goniotomy vs surgical goniotomy. A preliminary study in paired eyes. Arch Ophthalmo 1989;107:1773-6.

18 Elder MJ. Combined trabeculotomy-trabeculectomy compared with primary trabeculectomy for congenital glaucoma. Br f Ophthalmol 1994;78: mary trab

19 DeLuise VP, Anderson DR. Primary infantile glaucoma (congenital glaucoma). Surv Ophthalmol 1983;28:1-19.

20 Debnath SC, Teichmann KD, Salamah K. Trabeculectomy versus trabeculotomy in congenital glaucoma. Br F Ophthalmol 1989;73:608-11.

21 Khaw PT, Rice NSC, Baez KA. The congenital glaucomas. In: El Sayyad F, Spaeth GL, Shield MB, Hitchings RA, eds. The refractory glaucomas. Tokyo: Igaku-Shoin Medical Publishers Inc, 1995:1-21.

\title{
The challenge of HIV/AIDS related eye disease
}

As the predominant disease of the late 20th century, AIDS has thrived on great social change and globalisation of the world's economies and cultures. For most public health authorities, particularly in developing countries, the fact that the human immunodeficiency virus (HIV) affects the eye is simply a curiosity. As yet, little interest in HIV/AIDS has been expressed by the international eye care nongovernmental organisations; perhaps this should change.

There is a large body of literature now which describes the ocular manifestations of HIV/AIDS in developed countries and tremendous strides have been made in our understanding of cytomegalovirus (CMV) retinitis. Many ophthalmologists are unaware that the pattern of ocular morbidity associated with HIV/AIDS in developed countries is not representative of the epidemiology of the disease in developing countries. Investigations such as that carried out in Uganda and Malawi by Waddell and colleagues and reported in this issue of the BFO (p 503) are an important contribution to our understanding of the ocular manifestations of HIV/AIDS in Africa. This report and others from east Africa and South America make it clear that the epidemiology of the ocular manifestations of HIV/AIDS is not well understood. There have been no reports from west Africa, where HIV-2 infection predominates. There is a real paucity of information from Asia where, by the year 2000 , it is estimated that there will be 1.3 million HIV infections per year, over $60 \%$ of the world's total.

As reports by Kestelyn et $a l^{1}$ and Lewallen et $a l^{2}$ have demonstrated, CMV retinitis is relatively rare in Africa; this is probably due to the fact that mortality often occurs early in the course of HIV infection, before clinical AIDS develops. ${ }^{3}$ In developed countries, however, life expectancy after HIV seroconversion has increased to around 12 years; new classes of prophylactic drugs are delaying the onset of AIDS defining illnesses (although CMV retinitis is not one 
of these). In both developed and developing countries we could witness an increase in the incidence of $C M V$ retinitis as more patients live long enough to acquire the disease. Furthermore, in developed countries, life expectancy after CMV retinitis diagnosis has increased from an average of 5 months (1988) to 15 months (1996).

As Waddell and colleagues note, conjunctival squamous cell carcinomas do not appear to be a common finding in HIV/AIDS patients, even though there has been a substantial growth in their numbers and approximately three quarters of these patients are infected with HIV. Conjunctival squamous cell carcinomas are often not recognised or may be confused with pinguecula. On the other hand, herpes zoster ophthalmicus, whose incidence is unknown, is now recognised by the ophthalmic community and often by the general population to have a strong association with HIV in young individuals. There are likely to be other familiar viruses or disease entities which, coupled with HIV, will lead to atypical disease presentation. One must wonder what effect the HIV epidemic could have on the incidence (and presentation) of herpes simplex keratitis in areas where this has been reported to be very high. As Waddell and colleagues suggest, HIV infection in the community may promote transmission of other infective agents, such as tuberculosis, in the HIV negative community. Epidemiological and clinical investigations of eye pathology in HIV/AIDS patients in developing countries would lead to a better understanding of these problems.

Besides trying to clarify the epidemiology of the ocular manifestations of HIV/AIDS, we should be aware of the impact of HIV/AIDS on eye care services everywhere. The most obvious consequence is the increased burden on these services. In 1995 at St Paul's Hospital in Vancouver, AIDS related eye disease accounted for 1200 patient visits per year, $22 \%$ of all patient visits. In Canada the increase in life expectancy after diagnosis of CMV retinitis has led to a substantial increase in per patient expenses for antiviral agents, from an estimated $\$ 100000$ per case to $\$ 375000$ per case. In developing countries these drugs simply aren't available, but the burden on staffing resources is growing. In an informal survey in east Africa, ophthalmologists reported spending anywhere from $5 \%$ to $40 \%$ of their time dealing with HIV/AIDS related pathology. A second, less obvious consequence of the epidemic is that resources have been diverted to AIDS control from most health sectors; blindness is not perceived to be as crucial to a nation's health as AIDS control and many government agencies have reduced their allocation to blindness prevention. Finally, there is the fact that health workers, being part of the middle class, are part of the 'high risk' group in Africa. A number of health workers in Africa, including some eye care professionals, have succumbed to HIV/AIDS. Some organisations (governmental and non-governmental) have had to face the unpleasant prospect of testing for HIV before admitting candidates to special training programmes.

The evolving HIV epidemic will have an impact on ophthalmology and blindness prevention; by anticipating the impact, we may be able to mitigate some of the damage.

PAUL COURTRIGHT

British Columbia Centre for Epidemiologic and

International Ophthalmology,

University of British Columbia, St Paul's Hospital, 1081 Burrard Street, Vancouver,

BC, Canada V6Z 1 Y 6

1 Kestelyn P, Van de Perre P, Rouvroy D, LePage P, Bogaerts J, Nzaramba D, et al. A prospective study of the ophthalmologic findings in the acquired immune deficiency syndrome in Africa. Am $₹$ Ophthalmol 1985;100:230-8. 2 Lewallen S, Kumwenda J, Maher D, Harries AD. Retinal findings in Malawian patients with AIDS. Br $\mathcal{F}$ Ophthalmol 1994;78:757-9.

3 Gilks CF. The clinical challenge of the HIV epidemic in the developing world. Lancet 1993;342:1037-9. 